\title{
Different hypertension thresholds and cognitive decline: a pooled analysis of three ageing cohorts
}

\author{
Yanjun Ma ${ }^{1,2,3 \dagger}$, Rong Hua ${ }^{1,2 \dagger}$, Zhenchun Yang ${ }^{4}$, Baoliang Zhong ${ }^{5}$, Li Yan ${ }^{6 *}$ and Wuxiang Xie ${ }^{1,2^{*}}$
}

\begin{abstract}
Background: The 2017 American College of Cardiology (ACC)/American Heart Association (AHA) guidelines for high blood pressure (BP) in adults came up with a new definition of hypertension with a threshold BP level of 130/ $80 \mathrm{mmHg}$. But the 2018 European Society of Cardiology (ESC)/European Society of Hypertension (ESH) guidelines adhered to a conventional hypertension definition as $\mathrm{BP} \geq 140 / 90 \mathrm{mmHg}$. We aimed to compare the trajectories of cognitive decline between participants with BP $<130 / 80 \mathrm{mmHg}$ in all BP measurement waves and others with all $\mathrm{BP}<140 / 90 \mathrm{mmHg}$.

Methods: This pooled analysis involved middle-aged and older participants from three nationally representative ageing cohorts, including the Health and Retirement Study (HRS), the English Longitudinal Study of Ageing (ELSA), and the China Health Retirement Longitudinal Study (CHARLS). Participants were divided into the Normal (BP < 130/80 $\mathrm{mmHg}$ on all occasions throughout the study), the Borderline (BP $<140 / 90 \mathrm{mmHg}$ on all occasions throughout the study but not in the Normal group), and the High (the rest of participants) BP groups. Global cognitive Z score was calculated from tests on memory, executive function, and orientation.
\end{abstract}

Results: A total of 17,590 participants (HRS 6964, median follow-ups 12 years; ELSA 5334, median follow-ups 16 years; CHARLS 5292, median follow-ups 7 years) were included. No significant difference in global cognitive decline rate was detected between the Normal and the borderline groups (men, pooled $\beta=-0.006$ standard deviation [SD]/year; 95\% confidence interval $[\mathrm{Cl}],-0.020$ to $0.008 ; P=0.377$; women, pooled $\beta=0.006 \mathrm{SD} /$ year; $95 \% \mathrm{Cl}-0.005$ to $0.018 ; P=$ 0.269). Participants in the High group had a significantly faster cognitive decline (men, pooled $\beta=-0.011 \mathrm{SD} /$ year; $95 \%$ $\mathrm{Cl}-0.020$ to $-0.002 ; P=0.013$; women, pooled $\beta=-0.017 \mathrm{SD} /$ year; $95 \% \mathrm{Cl}-0.026$ to $-0.008 ; P<0.001$ ) than that in the Borderline group.

Conclusions: Individuals in the Borderline group did not experience significantly faster cognitive decline compared with those in the Normal group. It might not be necessary for individuals with borderline BP (between 130/80 and 140/90 $\mathrm{mmHg}$ ) to initiate antihypertension therapy in consideration of cognitive decline.

Keywords: Blood pressure, Hypertension, Cognitive dysfunction

\footnotetext{
* Correspondence: I.yan@pku.edu.cn; xiewuxiang@hsc.pku.edu.cn

†Yanjun Ma and Rong Hua contributed equally to this work.

${ }^{6}$ National School of Development, Peking University, Beijing, China

'Peking University Clinical Research Institute, Peking University First Hospital, Beijing, China

Full list of author information is available at the end of the article
}

(c) The Author(s). 2021 Open Access This article is licensed under a Creative Commons Attribution 4.0 International License, which permits use, sharing, adaptation, distribution and reproduction in any medium or format, as long as you give appropriate credit to the original author(s) and the source, provide a link to the Creative Commons licence, and indicate if changes were made. The images or other third party material in this article are included in the article's Creative Commons licence, unless indicated otherwise in a credit line to the material. If material is not included in the article's Creative Commons licence and your intended use is not permitted by statutory regulation or exceeds the permitted use, you will need to obtain permission directly from the copyright holder. To view a copy of this licence, visit http://creativecommons.org/licenses/by/4.0/ The Creative Commons Public Domain Dedication waiver (http://creativecommons.org/publicdomain/zero/1.0/) applies to the data made available in this article, unless otherwise stated in a credit line to the data. 


\section{Background}

The 2017 American College of Cardiology (ACC)/ American Heart Association (AHA) guidelines for high blood pressure (BP) in adults came up with a new definition of hypertension with a threshold BP level of 130/ $80 \mathrm{mmHg}$ [1]. But the 2018 European Society of Cardiology (ESC)/European Society of Hypertension (ESH) guidelines adhered to a conventional hypertension definition as $\mathrm{BP} \geq 140 / 90 \mathrm{mmHg}$ [2]. This difference leads to distinct strategies for individuals with a BP between the two thresholds and might impact on primary prevention of a large group of hypertension-related diseases, including dementia $[1,2]$. As one of the most severe disorders in later life, dementia affected 50 million people and imposed a financial burden of US\$1 trillion globally in 2018 [3]. Since people live longer, both the above figures are still increasing drastically [3]. Dementia cannot be cured but can be prevented or delayed during its long period of the preclinical phase [4].

Large epidemiological studies have demonstrated that midlife hypertension was significantly associated with an increased rate of cognitive decline and higher dementia risk in later life [5, 6]. Midlife hypertension, defined as BP $\geq 140 / 90 \mathrm{mmHg}$, was related to 1.55 -fold excess global cognitive decline risk and 1.20-fold elevated dementia risk according to a systematic review of prospective studies [6]. $\mathrm{BP}$ lowering has been proved to reduce the risk of cognitive impairment or dementia among patients with hypertension [1, 2]. But most of the previous studies on the association between hypertension and cognitive decline were based on the conventional hypertension definition as $\mathrm{BP} \geq 140 / 90 \mathrm{mmHg}[1,2,6,7]$. The association of borderline hypertension, with BP between 130/80 and 140/90 $\mathrm{mmHg}$, and cognitive decline remains not elucidated. What is more, the role of long-term BP in cognitive decline was rarely investigated. Herein, we sought to compare the trajectories of cognitive decline between two groups: (1) the Normal BP group included participants with $\mathrm{BP}<130 / 80 \mathrm{mmHg}$ in all $\mathrm{BP}$ measurement waves; (2) the Borderline BP group included participants with all $\mathrm{BP}<140 / 90 \mathrm{mmHg}$, except those in the Normal BP group. Our hypothesis was that individuals in the Normal BP group would experience slower cognitive decline than those in the Borderline BP group.

\section{Methods}

\section{Study population}

The present study implemented a cross-sectional design using open-access data from three nationally representative longitudinal ageing cohorts: waves 8 to 14 (2006 to 2018) of the Health and Retirement Study (HRS), waves 0 to $9(1998 / 1999 / 2001$ to 2018/2019) of the English Longitudinal Study of Ageing (ELSA), and waves 1 to 4 (2011 to 2018) of the China Health Retirement
Longitudinal Study (CHARLS), which shared overall design and a large group of variables including BP and cognitive scores [8-13]. These three cohorts were conformed to the Declaration of Helsinki and approved by the Health Sciences and Behavioral Sciences Institutional Review Board at the University of Michigan, the London Multicentre Research Ethics Committee, and the Peking University Institutional Review Board, respectively. The HRS randomly enrolled individuals over age 50 in the USA via a multistage area probability sampling design since 199 2[14]. The ELSA sample was from the Health Survey for England (HSE), which randomly recruited individuals aged 50 years or older living in England using postcode [10, 14]. The CHARLS randomly selected Chinese residents aged 45 years or older via multistage probability sampling since 2011 [12]. All participants gave written informed consent and followed at 2-year, occasionally 3-year, intervals.

Wave 8 (2006) in the HRS, wave $1(2002 / 2003)$ in the ELSA, and wave 1 (2011) in the CHARLS were regarded as the baseline in the present study. The inclusion criteria in the present analysis were attending wave 8 in the HRS, wave 1 in the ELSA, or wave 1 in the CHARLS. The exclusion criteria included: (1) missing complete cognitive scores, or (2) having a confirmed diagnosis of dementia/psychiatric disorders at baseline, or (3) missing important covariate (sex), or (4) only taking BP measurement on $<3$ occasions, or (5) without follow-up cognitive scores.

\section{Blood pressure}

BP measurement was performed for half of the participants in waves $8,10,12$, and 14 and the other half in waves 9, 11, and 13 using Omron HEM-780 Monitor in the HRS; waves $0,2,4,6$, and 8 in the ELSA using Omron HEM-907 Monitor; and waves 1 to 4 in the CHARLS using Omron HEM-7200 Monitor. In the ELSA, BP at wave 0 was regarded as the baseline BP since no BP measurement was conducted at wave 1. Participants were asked to remain seated and quiet during the measurement. The interviewers placed the cuff on the participants' left arm. Three measurements were conducted at 1-min intervals in a single wave, the mean of which was used. The Normal BP group included participants with BP $<130 / 80 \mathrm{mmHg}$ in all BP measurement waves. Except those in the Normal BP group, other participants with all BP below 140/90 mmHg were in the Borderline BP group. The other participants were in the High BP group. In other words, participants in the Normal BP group had their BP persistently under the threshold of hypertension definition in the $\mathrm{ACC} /$ AHA guidelines. Participants in the Borderline BP group failed to keep their BP persistently under the ACC/AHA threshold, but successfully under the ESC/ESH 
threshold. The High BP group contained participants with $\mathrm{BP}$ reaching the ESC/ESH threshold on at least one occasion.

\section{Cognitive assessments}

Cognitive assessments were conducted in waves 8 to 14 in the HRS, waves 1 to 9 in the ELSA, and waves 1 to 4 in the CHARLS. Three cognitive domains were covered, including memory, executive function, and orientation.

Immediate and delayed recall of ten unrelated words was used for the memory test. One point was given for each word recalled in either immediate or delayed recall task. Orientation was evaluated by four questions on the year, the month, the date of the month, and the day of the week. The sum of correct answers was regarded as the orientation score. The scores of memory and orientation ranged 0 to 20 and 0 to 4, respectively. Executive function was assessed by the counting-backward test $(0$ to 2 points) and the Serial Sevens test (0 to 5 points) in the HRS (0 to 7 points in total); an animal fluency test in the ELSA; an intersecting pentagon copying test (0 or 3 points); and the Serial Sevens test (0 to 5 points) in the CHARLS (0 to 8 points in total). In the countingbackward test, participants counted backwards from 20 as quickly as they could. A successful count from 19 to 10 or 20 to 11 on the first try was given two points; otherwise, success on the second try was given one point. In the Serial Sevens test, participants counted backwards from 100 by sevens for five times. One point was given for each correct answer. In the animal fluency test, the participant was asked to name animals as many as he or she could in $1 \mathrm{~min}$. The score equalled the number of animals named, thus there was no upper limit of score range. In the intersecting pentagon copying test, participants were asked to observe and then draw a picture of two overlapping pentagons. A successful drawing was given three points. Both the validity and the reliability of these tests have been well documented [15-18]. Full details of these tests can be found in Additional file 1: Supplemental Methods.

To evaluate the global cognitive function, $Z$ scores were generated by two steps in each cohort. Step 1: the domain $Z$ scores were generated by standardizing to baseline. Each domain test score was subtracted by the mean and then divided by the standard deviation (SD) of the baseline domain scores. For instance, the mean and SD of executive function at baseline in the HRS were 5.84 and 1.35 , respectively. Then the executive $Z$ score at any wave was calculated as (original executive score at the wave - 5.84) / 1.35. Step 2: the global $Z$ score of an individual at each wave was calculated from the mean score of three domains by re-standardizing to baseline. This procedure to generate cognitive $Z$ scores has been widely accepted [15-20].

\section{Covariates}

A large group of potential confounders for the association between BP and cognitive function were selected for our analyses, including sex, age (years), race, body mass index (BMI, $\mathrm{kg} / \mathrm{m}^{2}$ ), education, cohabitation status, current smoking, alcohol consumption, exercise, depressive symptoms, antihypertension medication, diabetes, hypercholesterolemia, coronary heart disease, stroke, cancer, and chronic lung disease in the present analysis. Race was divided into white or not, thus race was not included in the analysis of the CHARLS. High level of education was defined as $\geq$ the senior level of high school or $\geq 12$ years of education. Cohabitation status was categorized as living alone or not. Current smoking indicated smoking currently or not. Once per week or a higher frequency of drinking was defined as alcohol consumption. Engaging in vigorous or moderate activities once weekly or more was regarded as physically active. Depressive symptoms were evaluated by an 8 -item version of the Center for Epidemiologic Studies Depression (CESD-8, one point for each item) in the HRS and the ELSA, and a 10-item version of the CESD (CESD-10, 0 to 3 points for each item) in the CHARLS. Participants with a score of $\geq 4$ in the CESD- 8 or $\geq 12$ in the CESD10 were regarded as having depressive symptoms [21, 22]. The proportion of waves reporting any antihypertension medication using in all attending waves was used. For example, if a participant attended four waves throughout the study and reported antihypertension medication using at two waves, then the proportion would be 0.5 . Chronic disease measures included selfreported physician-diagnosed diabetes (or current use of anti-diabetic therapy), coronary heart disease, stroke, cancer, and chronic lung disease. Hypercholesterolemia was defined as self-reported physician-diagnosed hypercholesterolemia, or self-reported use of lipid-lowering medication, or total cholesterol $\geq 240 \mathrm{mg} / \mathrm{dL}$ [23]. Full details of covariates can be found in Additional file 1: Supplemental Methods.

\section{Statistical analysis}

The results are presented as the mean $\pm \mathrm{SD}$ or the median with the interquartile range (IQR) for continuous variables and numbers (percentage) for categorical variables. Association between BP group and global or domain cognitive $Z$ score decline (SD/year) during followup in a single cohort was evaluated by linear mixed models including BP group, time (duration since baseline), BP group $\times$ time, age at baseline, and other covariates mentioned above. The Borderline BP group was regarded as the reference group. The cognitive decline rate of the Normal or the High BP group compared with that of the Borderline BP group was indicated by the regression coefficient of BP group $\times$ time. Linear mixed 
models can also handle missing data. Random-effect meta-analyses were performed for the pooled estimates. The percentage of variation across cohorts due to heterogeneity rather than chance was indicated by the $I^{2}$ statistic in meta-analyses. The approach that pooling coefficients of linear mixed models has been used in previous studies [24-26].

Five sensitivity analyses were performed. The first excluded participants who ever reported antihypertension medication using either at baseline or during follow-up. The second excluded those with hypotension, defined as $\mathrm{SBP}<90 \mathrm{mmHg}$ or DBP $<60 \mathrm{mmHg}$, on at least one BP measurement occasion over the study. The third excluded individuals with stroke or coronary heart disease at baseline. The fourth included all participants who had complete baseline data, at least one reassessment of cognitive function, and BP measurements on $\geq 2$ occasions. The last sensitivity analysis was performed using original cognitive scores rather $Z$ scores. In addition, a nonresponse analysis was performed to compare the baseline characteristics between participants who were included and those who were excluded due to less than three BP measurements or no follow-up cognitive score.

All analyses were conducted by sex, using SAS (version 9.4; SAS Institute Inc) and STATA (version 11; Stata Corp LLC). All tests were two-sided with an alpha of 0.05 as the threshold for statistical significance.

\section{Results}

\section{Sample size and baseline characteristics}

Among 48,274 participants (HRS 18,469; ELSA 12,099; CHARLS 17,706) attending baseline surveys, 17,590 participants with complete baseline data, BP measurements on $\geq 3$ occasions, and at least one reassessment of cognitive function were included in our analyses, including 6964 from the HRS (mean age $66.3 \pm 8.0$ years, women 59.6\% [4154], median follow-up duration: 12.0 [IQR 10.0 to 12.0] years), 5334 from the ELSA (mean age $62.4 \pm$ 8.9 years, women $56.2 \%$ [2996], median follow-up duration 16 [IQR 12 to 16] years), and 5292 from the CHARLS (mean age $58.1 \pm 8.8$ years, women $52.1 \%$ [2759], median follow-up duration 7 [IQR 4 to 7] years). The number and proportion of participants completing planned BP measurement waves of each cohort are shown in Additional file 1: Table S1. BP groups, covariates, and baseline cognitive scores by domain are presented by sex in Table 1 and Additional file 1: Table S2. The three cohorts exhibited significant differences in baseline characteristics (Additional file 1: Table S2). The HRS participants were the oldest, had the highest proportion of those with high-level education, and had the highest prevalence of most chronic diseases (except chronic lung disease). The ELSA participants presented the highest systolic BP and had the highest proportion of the High BP group and alcohol consumption. The CHARLS participants were the youngest, exhibited the lowest body mass index and the highest memory cognitive score, but had the highest percentage of physical inactive, depressive symptoms, smoking, and chronic lung disease.

\section{BP group and cognitive decline}

Due to the considerable ( $I^{2}$ over $75 \%$ according to Cochrane Handbook) between-cohort heterogeneity in the pooled analysis of global cognitive decline between the Normal and the Borderline BP groups, subsequent analyses were performed by sex (Additional file 1: Fig. S1 and Table S3) [27]. After adjustment for covariates, no significant difference was detected for global cognitive decline rate between the Normal and the Borderline $\mathrm{BP}$ groups (men, pooled $\beta=-0.006 \mathrm{SD} /$ year; $95 \%$ confidence interval $[\mathrm{CI}],-0.020$ to $0.008 ; P=0.377$; women, pooled $\beta=0.006 \mathrm{SD} /$ year; $95 \% \mathrm{CI}-0.005$ to $0.018 ; P=$ 0.269; Fig. 1 and Tables 2 and 3). The High BP group presented a significantly faster global cognitive decline than the Borderline BP group (men, pooled $\beta=-0.011$ SD/year; $95 \% \mathrm{CI}-0.020$ to $-0.002 ; P=0.013$; women, pooled $\beta=-0.017 \mathrm{SD} /$ year; $95 \% \mathrm{CI}-0.026$ to -0.008 ; $P<0.001$; Fig. 1 and Tables 2 and 3). Similar trends were observed in analyses for single cognitive domains, except memory and orientation in men and executive function in women (where the difference between the High and the Borderline BP groups was not significant; Fig. 1 and Tables 2 and 3). Compared with individuals in the Normal BP group, those in the High BP experienced a significantly faster global cognitive decline in women (pooled $\beta=-0.023 \mathrm{SD} /$ year; $95 \% \mathrm{CI}-0.039$ to -0.006 ; $P=0.007$ ), while no significant difference was detected in men (pooled $\beta=-0.005 \mathrm{SD} /$ year; $95 \% \mathrm{CI}-0.015$ to $0.005 ; P=0.326$; Additional file 1: Fig. S2 [part A] and Table S4).

\section{Sensitivity analyses}

Sensitivity analyses covered 8102 participants who never used antihypertension medication, 14,620 without hypotension throughout the study, 14,448 without coronary heart disease or stroke at baseline, and 26,360 with $\mathrm{BP}$ measurement at $\geq 2$ occasions (Additional file 1: Tables S5 and S6). Besides, the results of sensitivity analyses using original cognitive scores are presented in Additional file 1: Tables S7 and S8. The differences in original cognitive score decline rate between BP groups were consistent with those in $Z$ scores. No significant difference in cognitive decline rate between the Normal and the Borderline BP groups was observed in any sensitivity analysis (Fig. 2; Additional file 1: Tables S5 to S8). 
Table 1 BP group and covariates of participants in analyses

\begin{tabular}{|c|c|c|c|c|c|c|c|c|c|}
\hline \multirow[t]{2}{*}{ Characteristic } & \multicolumn{2}{|c|}{ HRS $(n=6964)$} & \multirow[b]{2}{*}{$P$ value* } & \multicolumn{2}{|c|}{ ELSA $(n=5334)$} & \multirow[b]{2}{*}{$P$ value* } & \multicolumn{2}{|c|}{ CHARLS $(n=5292)$} & \multirow[b]{2}{*}{$P$ value } \\
\hline & $\begin{array}{l}\text { Men } \\
(n=2810)\end{array}$ & $\begin{array}{l}\text { Women } \\
(n=4154)\end{array}$ & & $\begin{array}{l}\text { Men } \\
(n=2338)\end{array}$ & $\begin{array}{l}\text { Women } \\
(n=2996)\end{array}$ & & $\begin{array}{l}\text { Men } \\
(n=2533)\end{array}$ & $\begin{array}{l}\text { Women } \\
(n=2759)\end{array}$ & \\
\hline Age (years) & $66.4 \pm 7.9$ & $66.2 \pm 8.0$ & 0.420 & $62.2 \pm 8.7$ & $62.5 \pm 9.1$ & 0.202 & $59.4 \pm 8.6$ & $56.9 \pm 8.8$ & $<0.001$ \\
\hline White (\%) & $2376(84.6)$ & $3369(81.1)$ & $<0.001$ & $2291(98.0)$ & $2946(98.3)$ & 0.355 & $0(\%)$ & $0(\%)$ & \\
\hline BP group (\%) & & & $<0.001$ & & & $<0.001$ & & & $<0.001$ \\
\hline Normal & $378(13.5)$ & $736(17.7)$ & & $186(8.0)$ & $395(13.2)$ & & $598(23.6)$ & $820(29.7)$ & \\
\hline Borderline & $700(24.9)$ & $1044(25.1)$ & & $460(19.7)$ & $502(16.8)$ & & $616(24.3)$ & $612(22.2)$ & \\
\hline High & $1732(61.6)$ & $2374(57.1)$ & & $1692(72.4)$ & $2099(70.1)$ & & $1319(52.1)$ & $1327(48.1)$ & \\
\hline BMI $\left(\mathrm{kg} / \mathrm{m}^{2}\right)$ & $29.4 \pm 4.8$ & $29.5 \pm 6.0$ & 0.551 & $27.5 \pm 3.8$ & $27.5 \pm 5.0$ & 0.814 & $23.1 \pm 3.5$ & $24.2 \pm 3.8$ & $<0.001$ \\
\hline $\begin{array}{l}\text { Systolic blood pressure } \\
(\mathrm{mmHg})\end{array}$ & $133.4 \pm 18.4$ & $128.4 \pm 19.7$ & $<0.001$ & $141.9 \pm 17.6$ & $139.7 \pm 20.2$ & $<0.001$ & $129.9 \pm 19.8$ & $129.4 \pm 21.4$ & 0.313 \\
\hline $\begin{array}{l}\text { Diastolic blood pressure } \\
(\mathrm{mmHg})\end{array}$ & $80.4 \pm 11.1$ & $79.4 \pm 11.3$ & 0.010 & $81.6 \pm 11.3$ & $74.8 \pm 11.6$ & $<0.001$ & $76.2 \pm 12.2$ & $75.5 \pm 11.9$ & 0.049 \\
\hline High level of education (\%) & $2326(82.8)$ & $3384(81.5)$ & 0.162 & $1043(44.6)$ & $832(27.8)$ & $<0.001$ & $387(15.3)$ & $193(7.0)$ & $<0.001$ \\
\hline Living alone (\%) & $457(16.3)$ & $1533(36.9)$ & $<0.001$ & $491(21.0)$ & $1101(36.7)$ & $<0.001$ & $206(8.1)$ & $326(11.8)$ & $<0.001$ \\
\hline Current smoking (\%) & $344(12.2)$ & $473(11.4)$ & 0.276 & $333(14.2)$ & $489(16.3)$ & 0.037 & $1866(73.7)$ & $203(7.4)$ & $<0.001$ \\
\hline Alcohol consumption (\%) & $1334(47.5)$ & $1233(29.7)$ & $<0.001$ & $1740(74.4)$ & $1595(53.2)$ & $<0.001$ & $1161(45.8)$ & $192(7.0)$ & $<0.001$ \\
\hline Physically active (\%) & $2399(85.4)$ & $3161(76.1)$ & $<0.001$ & $2027(86.7)$ & $2397(80.0)$ & $<0.001$ & $786(31.0)$ & $843(30.6)$ & 0.708 \\
\hline Depressive symptoms (\%) & $231(8.2)$ & $603(14.5)$ & $<0.001$ & $207(8.9)$ & $500(16.7)$ & $<0.001$ & $461(18.2)$ & $797(28.9)$ & $<0.001$ \\
\hline $\begin{array}{l}\text { Taking antihypertension } \\
\text { medication (\%) }\end{array}$ & $1982(70.5)$ & $2958(71.2)$ & 0.543 & $1203(51.5)$ & $1512(50.5)$ & 0.474 & $573(25.6)$ & $555(23.6)$ & 0.124 \\
\hline \multicolumn{10}{|l|}{ History of diseases } \\
\hline Hypertension (\%) & $1729(61.5)$ & $2502(60.2)$ & 0.276 & $797(34.1)$ & $1055(35.2)$ & 0.392 & $986(38.9)$ & $1081(39.2)$ & 0.85 \\
\hline Diabetes (\%) & $522(18.6)$ & $671(16.2)$ & 0.008 & $165(7.1)$ & $129(4.3)$ & $<0.001$ & $122(4.8)$ & $169(6.1)$ & 0.037 \\
\hline Hypercholesterolemia (\%) & $1343(47.8)$ & $1656(39.9)$ & $<0.001$ & $829(35.5)$ & $1132(37.8)$ & 0.08 & $384(15.2)$ & $463(16.8)$ & 0.108 \\
\hline Heart disease (\%) & $682(24.3)$ & $707(17.0)$ & $<0.001$ & $433(18.5)$ & $441(14.7)$ & $<0.001$ & $235(9.3)$ & $344(12.5)$ & $<0.001$ \\
\hline Stroke $(\%)$ & $128(4.6)$ & $133(3.2)$ & 0.004 & $63(2.7)$ & $75(2.5)$ & 0.662 & $47(1.9)$ & $38(1.4)$ & 0.167 \\
\hline Cancer (\%) & $386(13.7)$ & $472(11.4)$ & 0.003 & $92(3.9)$ & $202(6.7)$ & $<0.001$ & $17(0.7)$ & $28(1.0)$ & 0.174 \\
\hline Chronic lung disease (\%) & $177(6.3)$ & $341(8.2)$ & 0.003 & $103(4.4)$ & $154(5.1)$ & 0.214 & $278(11.0)$ & $232(8.4)$ & 0.002 \\
\hline \multicolumn{10}{|l|}{ Cognitive scores } \\
\hline Memory & $10.0 \pm 3.1$ & $10.9 \pm 3.2$ & $<0.001$ & $10.1 \pm 3.2$ & $10.5 \pm 3.2$ & $<0.001$ & $15.2 \pm 4.7$ & $15.0 \pm 4.9$ & 0.071 \\
\hline Executive $^{+}$ & $7(5-7)$ & $6(5-7)$ & $<0.001$ & $21.1 \pm 6.3$ & $20.3 \pm 6.0$ & $<0.001$ & $7(5-8)$ & $5(3-8)$ & $<0.001$ \\
\hline Orientation & $4(4-4)$ & $4(4-4)$ & $<0.001$ & $4(4-4)$ & $4(4-4)$ & 0.003 & $4(3-4)$ & $3(2-4)$ & $<0.001$ \\
\hline
\end{tabular}

Data are presented as mean $\pm \mathrm{SD}, n(\%)$, or median (IQR)

* $P$ value for differences between men and women

${ }^{+}$The executive scores are presented in different forms due to different assessment methods

$H R S$, the Health and Retirement Study; ELSA, the English Longitudinal Study of Ageing; CHARLS, the China Health Retirement Longitudinal Study; BP, blood pressure; $B M I$, body mass index

\section{Non-response analyses}

A total of 20,700 participants (HRS 7770; ELSA 6329; CHARLS 6601) were excluded for $<3$ times BP measurement throughout the study or no follow-up cognitive score (Fig. 3). The excluded participants presented features as follows in all the three cohorts: older, had higher systolic BP, lower level of education, more likely to live alone, less active in physical activity, higher rate of self-reported coronary heart disease, and had lower executive scores (Additional file 1: Table S9).

\section{Discussion}

In this pooled study of the HRS, the ELSA, and the CHARLS with large nationally representative samples, we observed a significantly faster global cognitive decline in the High BP group than that in the Borderline BP group after adjustment, whereas no significant difference in global cognitive decline rate was detected between the Normal and the Borderline BP groups. These findings stand in most single cognitive domains and sensitivity analyses. As far as we know, the present study is one of 


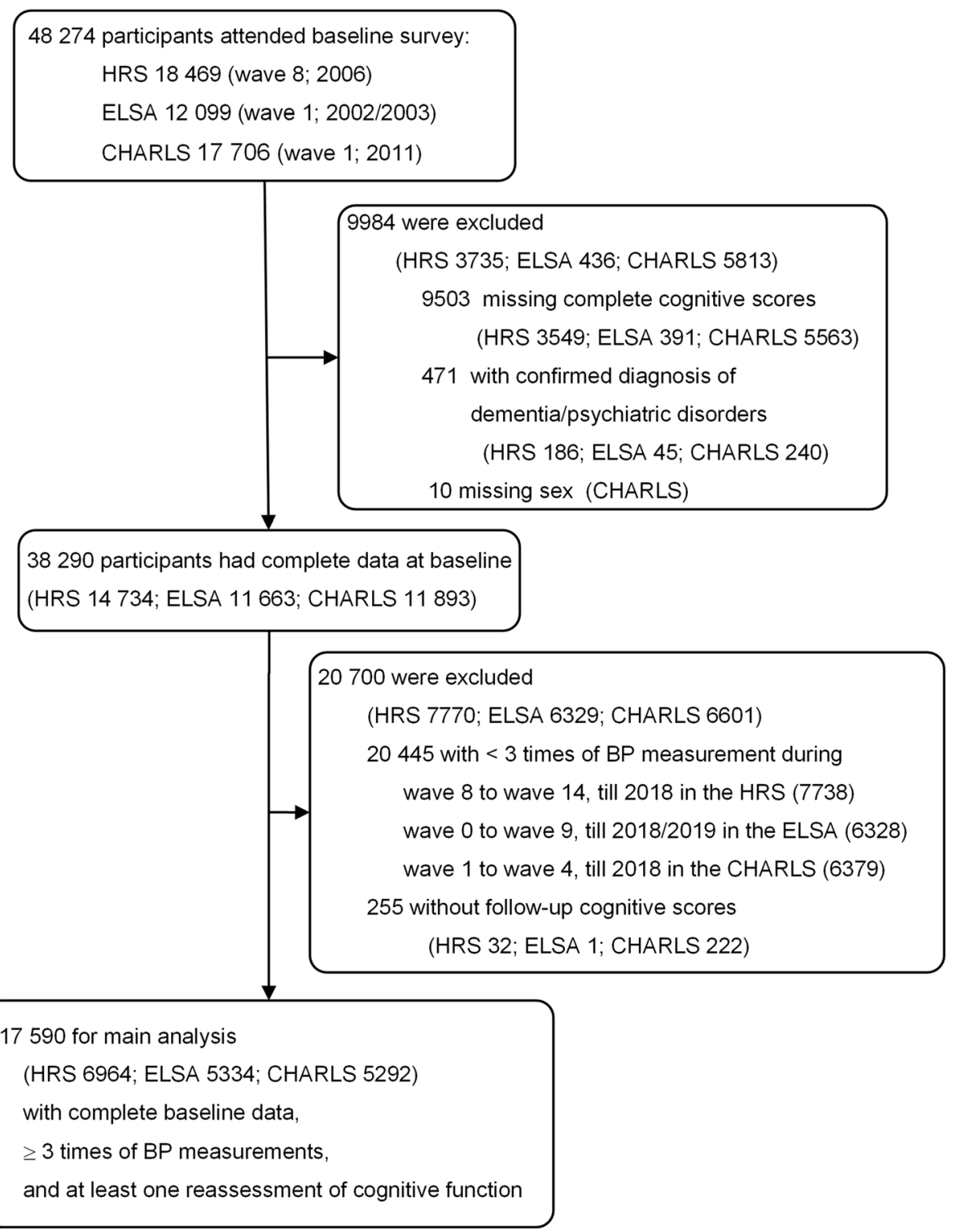

Fig. 1 Flow chart of participant selection for this study

the first and largest studies to analyze the association between long-term $\mathrm{BP}$ and cognitive decline rate regarding the different hypertension thresholds of the ACC/AHA guidelines and the ESC/ESH guidelines.

The findings in this study further contribute to the association between hypertension and cognitive function. A systematic review of 209 prospective studies in 2020 revealed a significant association between midlife hypertension and global cognitive function using low-tomoderate evidence [6]. This review used binary outcomes and did not focus on the association between hypertension and cognitive decline rate [6]. Another systematic review in 2020 collected data from randomized clinical trials and demonstrated a significantly lower risk of dementia or cognitive impairment for individuals using antihypertensive agents compared with control [28]. No significant association between BP lowering and change in cognitive scores was detected in the metaanalysis of eight trials [28]. Consistent with our results, Gottesman et al. reported that midlife hypertension at baseline was associated with faster global cognitive decline in a 20-year cohort [29]. In a 2-year study among individuals with mild cognitive impairment, Goldstein et al. grouped participants using an approach that was partly similar to what we used [30]. They found that cognitive function of individuals with hypertension on 


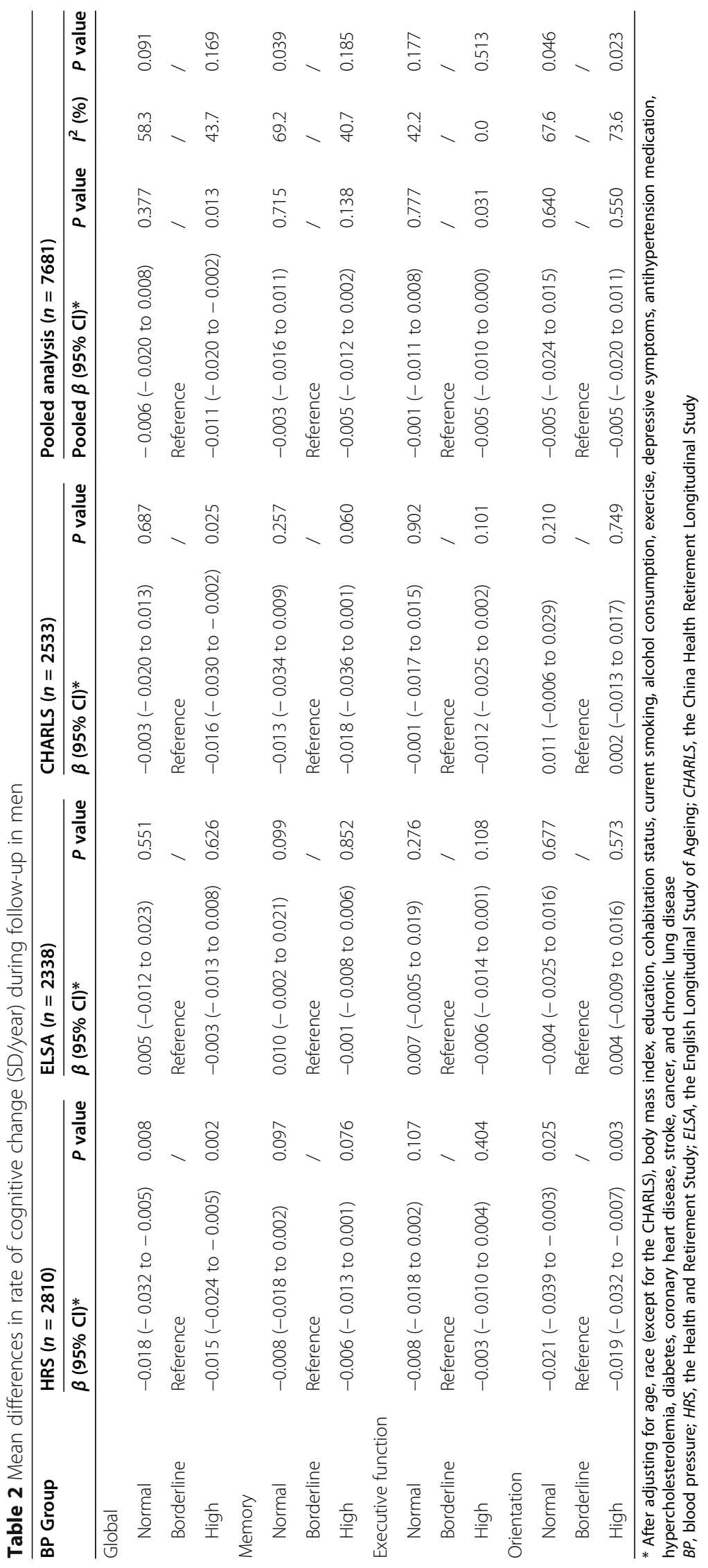




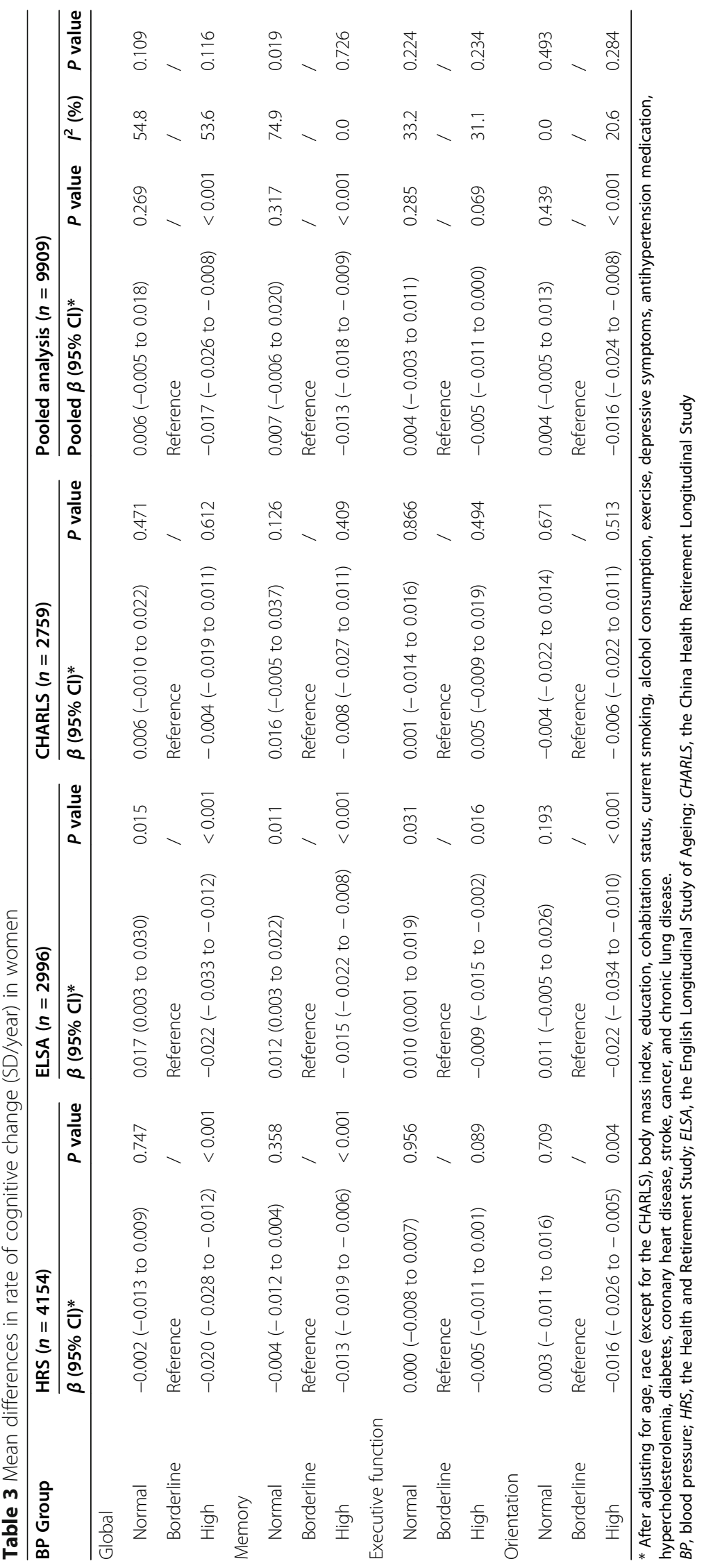




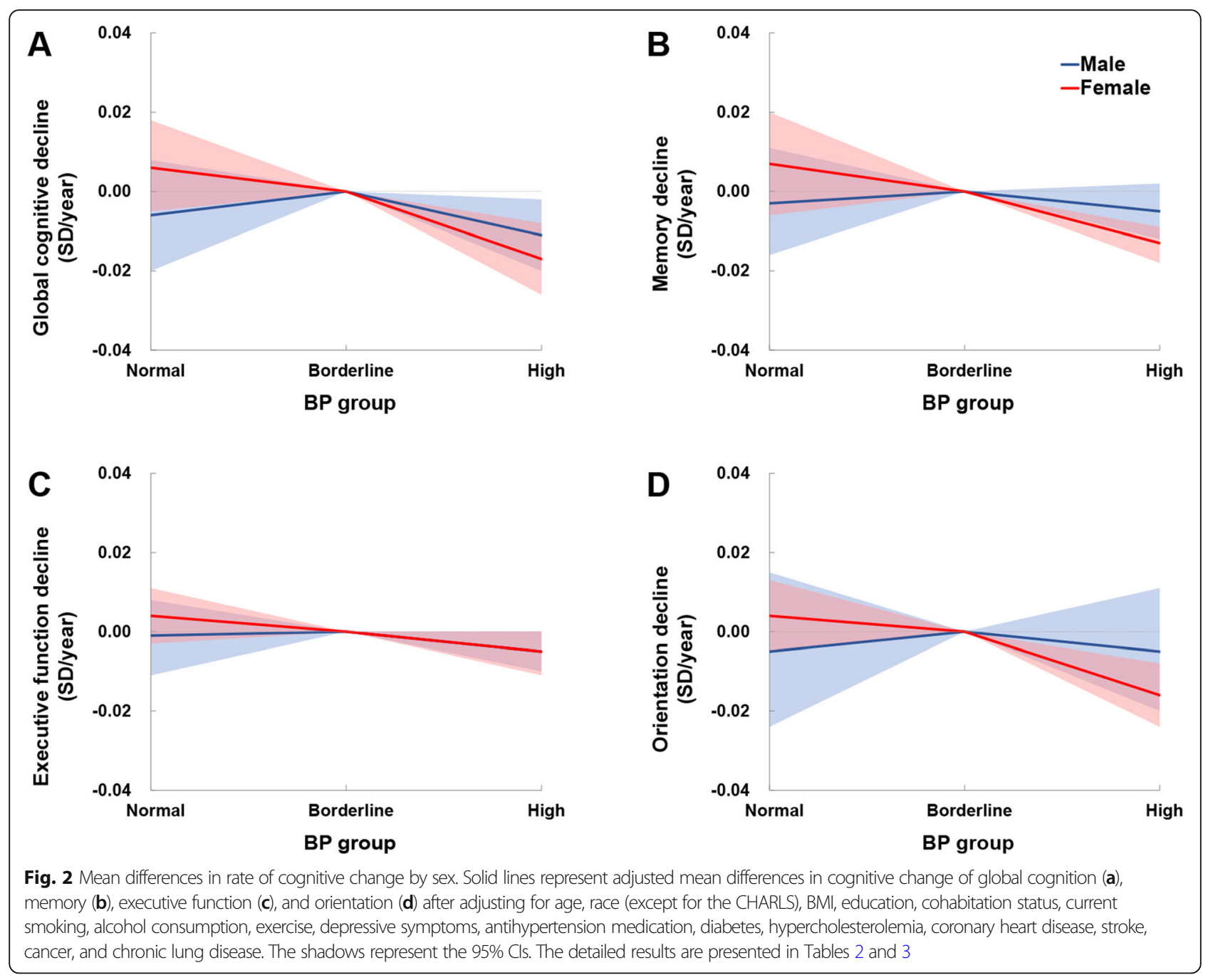

two or three occasions declined significantly faster than those with $\mathrm{BP}<140 / 90 \mathrm{mmHg}$ on all three occasions [30]. Noteworthy, all the aforementioned studies defined hypertension as BP $\geq 140 / 90 \mathrm{mmHg}$ and, except that by Goldstein et al., only used baseline BP. The present study observed a significant difference in global cognitive decline rate between the Borderline and the High BP groups. According to previous studies, a clinically significant change was defined as a decline of $0.5 \mathrm{SD}[31,32]$. The 95\% CI of global cognitive decline difference between the High and the Borderline BP groups would cover this magnitude in 25 years for men and in 20 years for women. The present study innovatively set the Borderline BP group of individuals with long-term BP under $140 / 90 \mathrm{mmHg}$ but at least one measurement reaching $130 / 80 \mathrm{mmHg}$ among all the 3 to 5 occasions. This grouping approach allowed us to address the distinction between hypertension management guidelines and compare individuals with BP under different thresholds. No significant difference in pooled global cognitive decline rate between the Normal and the Borderline BP groups was observed in main or sensitivity analyses. Therefore, among individuals with BP under the threshold of the ESC/ESH guidelines $(140 / 90 \mathrm{mmHg})$, long-term BP under that of the threshold of the ACC/AHA guidelines $(130 / 80 \mathrm{mmHg})$ did not make a significant difference in cognitive decline rate.

Remarkably, there have been studies reporting the association between low BP and poorer cognition $[6,33]$. An $\mathrm{SBP} \leq 128 \mathrm{mmHg}$ has been associated with faster cognitive decline in a cohort [33]. A recent systematic review also suggested that a DBP between 90 and 100 $\mathrm{mmHg}$ is an optimum level in older individuals [6]. Thus, we conducted a sensitivity analysis excluding all participants who ever presented hypotension on any BP measurement occasions throughout the study. In participants without hypotension, no significant difference was observed in the global cognitive decline rate between the 


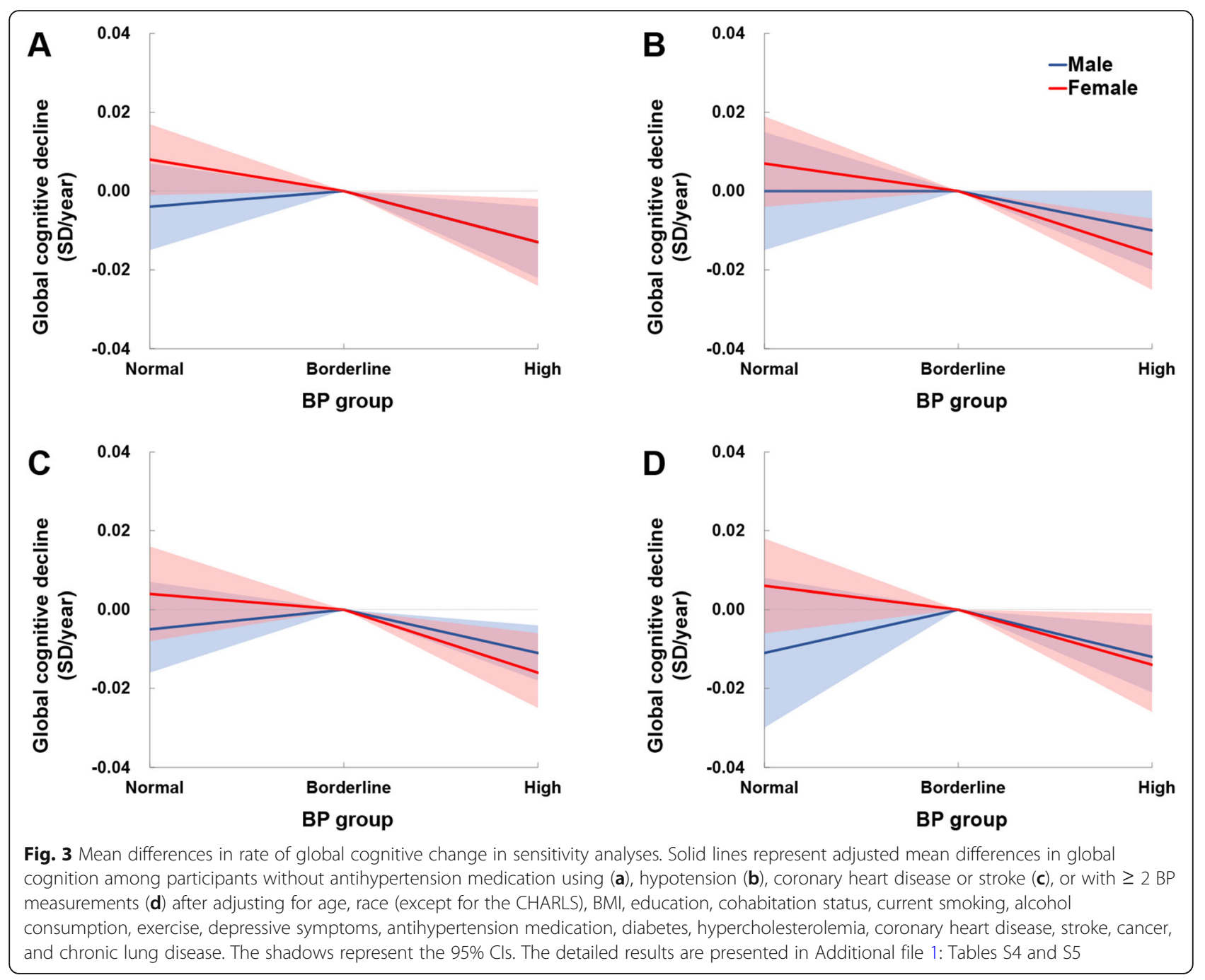

Normal and the Borderline BP groups. Compared with the Borderline BP group, the High BP group exhibited a marginal significantly faster global cognitive decline in men (pooled $\beta=-0.010 \mathrm{SD} /$ year; $95 \% \mathrm{CI}-0.020$ to $0.000 ; P=0.058$; Additional file 1: Table S4) and significantly in women (pooled $\beta=-0.016 \mathrm{SD} /$ year; $95 \% \mathrm{CI}-$ 0.025 to $-0.007 ; P<0.001$; Additional file 1 : Table S5) in the sensitivity analysis.

Several mechanisms have been indicated responsible for the association between BP and cognitive decline. Cortical white matter lesions and microvascular damage in the brain have been widely accepted as the mediating factors between hypertension and cognition $[1,34,35]$. Hypertension with BP $\geq 140 / 90 \mathrm{mmHg}$ was associated with increased white matter lesions in a communitybased study [34]. And arterial stiffening that was caused by long-standing hypertension might lead to small vessel ischemic disease in the brain [35]. Brain volume reduction has also been indicated as another manifestation of brain damage caused by hypertension in a systematic review [36]. What is more, a review suggested that low BP might cause cerebral hypoperfusion and then accelerate cognitive decline [37].

The foremost strength of the present study is repeated $\mathrm{BP}$ measurements during long follow-up. Most previous cohort studies evaluating the association between BP and cognitive decline or dementia only employed the BP at baseline [7, 29, 38-43]. A grouping approach using multiple BP measurements employed has also been adopted in a few studies, which was similar to but distinct from what we used [30,44]. In the present study, BP measurements on at least three occasions made it possible to evaluate the association between long-term $\mathrm{BP}$ maintenance and cognitive decline. BP maintenance might be more clinically relevant than baseline BP for the following two reasons. On the one hand, the association between visit-to-visit variability in BP and cognitive decline has been demonstrated $[45,46]$. On the 
other hand, failed BP maintenance under the hypertension threshold would initiate antihypertensive therapy. Thus, the present work is a useful supplement to previous studies on BP and cognitive decline. Second, the three large nationally representative cohorts from the US, England, and China enhance the certainty and generalizability of results. Third, the primary outcome, the decline rate of global cognitive $Z$ score, was calculated from cognitive assessments covering three domains, memory, executive function, and orientation. It would be more sensitive to detect cognitive changes than binary outcomes such as dementia incidence.

This study has several limitations. First, the inherent limitation of observational study restricts this work from confirming a causal relationship. Although there has been substantial evidence from randomized trials supporting the effect of BP levels on cognitive function [6, 28], a reversed causality still could not be completely ruled out. Second, among 38,290 individuals with complete data at baseline, only 17,590 (45.9\%) individuals were included in the main analysis, which would introduce selection bias and undermine the generalizability of our findings. Nonresponse analysis showed that participants who were excluded due to less than three BP measurements or no follow-up cognitive score were older and less healthy. To address this concern, sensitivity analysis among individuals with BP measurement on at least two occasions was conducted. This sensitivity analysis included 26,360 of $38,290(68.8 \%)$ participants with complete baseline data and yielded findings in keeping with that in the main analysis. Third, isolated tests, rather than a comprehensive test, were used to evaluate cognitive function. A subtle cognitive decline might not be detected due to insufficient sensitivity. Although the three cohorts shared the same tests on memory and orientation, the executive function was evaluated using different tests. To be exact, the executive function was assessed by the Serial Sevens test and the counting-backward test in the HRS; the animal fluency test in the ELSA; the Serial Sevens test; and an intersecting pentagon copying test in the CHARLS. $Z$ scores were used to evaluate the global cognitive function, while $Z$ scores were subjected to various distributions of original cognitive scores, especially those from different executive function tests. Besides, $Z$ scores caused difficulty in understanding the difference in cognitive decline rate. Thereby, analyses using the original cognitive scores were conducted. The results in Additional file 1: Tables S7 and S8 are presented as points/year for better understanding. For instance, the memory score in the High BP group would reduce faster by 0.044 points/year compared to that in the Borderline BP group for women, and one point in the memory test stands for a recalled word. Fourth, although a large group of covariates had been measured and adjusted in this study, there were still some unmeasured confounding factors such as $A P O E$ status and reduced renal function, which might confound the results. Fifth, there was inherent between-cohort heterogeneity, which might come from the significantly different covariates listed in Additional file 1: Table S2, the discrepancy in executive function tests, and other unmeasured factors. Due to considerable ( $I^{2}$ over $\left.75 \%\right)$ between-cohort heterogeneity in the pooled analysis of global cognitive decline, most analyses were conducted by sex, while moderate heterogeneity $\left(I^{2}\right.$ between $30 \%$ and $\left.60 \%\right)$ persisted [27]. Sixth, white coat hypertension could not be excluded and might introduce measurement bias.

\section{Conclusions}

The Borderline BP group was associated with significantly slower cognitive decline compared with the High BP group but not associated with a significantly different cognitive decline rate compared with the Normal BP group. The findings from this study indicated that it might not be necessary for individuals with borderline BP (between 130/80 and $140 / 90 \mathrm{mmHg}$ ) to initiate antihypertension therapy in consideration of cognitive decline. Prospective observational and interventional studies on the association between long-term BP and cognitive decline are warranted.

\section{Abbreviations \\ ACC: American College of Cardiology; AHA: American Heart Association; BMI: Body mass index; BP: Blood pressure; CESD: Center for Epidemiologic Studies Depression; CHARLS: China Health Retirement Longitudinal Study; Cl: Confidence interval; ELSA: English Longitudinal Study of Ageing; ESC: European Society of Cardiology; ESH: European Society of Hypertension; HRS: Health and Retirement Study; IQR: Interquartile range; SD: Standard deviation}

\section{Supplementary Information}

The online version contains supplementary material available at https://doi. org/10.1186/s12916-021-02165-4.

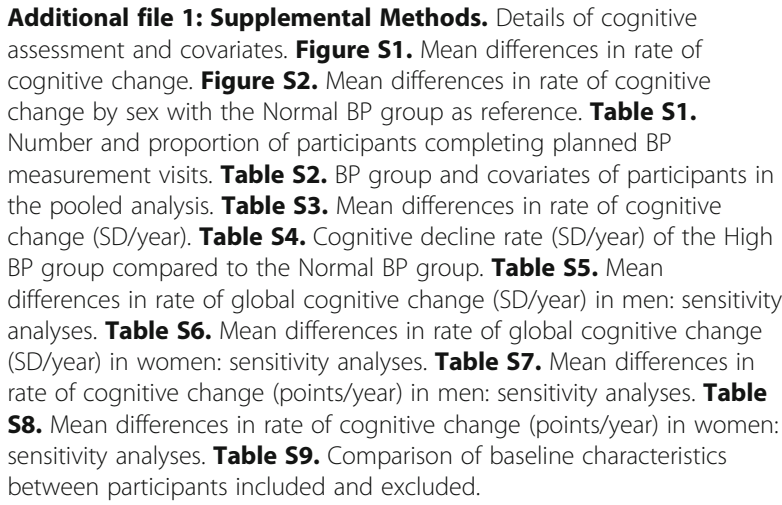

Additional file 1: Supplemental Methods. Details of cognitive assessment and covariates. Figure S1. Mean differences in rate of cognitive change. Figure S2. Mean differences in rate of cognitive change by sex with the Normal BP group as reference. Table S1. Number and proportion of participants completing planned BP measurement visits. Table S2. BP group and covariates of participants in the pooled analysis. Table S3. Mean differences in rate of cognitive change (SD/year). Table S4. Cognitive decline rate (SD/year) of the High BP group compared to the Normal BP group. Table S5. Mean differences in rate of global cognitive change (SD/year) in men: sensitivity analyses. Table S6. Mean differences in rate of global cognitive change (SD/year) in women: sensitivity analyses. Table S7. Mean differences in rate of cognitive change (points/year) in men: sensitivity analyses. Table S8. Mean differences in rate of cognitive change (points/year) in women: sensitivity analyses. Table $\mathbf{5 9}$. Comparison of baseline characteristics between participants included and excluded.

\section{Acknowledgements}

We thank the original data creators, depositors, copyright holders, the funders of the data collections for the use of data from the Health and Retirement Study (waves 8 to 14), the English Longitudinal Study of Ageing (waves 0 to 9), and the China Health Retirement Longitudinal Study (waves 1 to 4). De-identified data of these cohorts are publicly available. The original 
data creators, depositors, or copyright holders bear no responsibility for the current analysis or interpretation.

\section{Authors' contributions}

WX and LY conceived the study and designed the statistical analyses. YM and RH did the statistical analyses and prepared the draft of the manuscript. $Z Y, B Z, L Y$, and $W X$ substantively revised the manuscript. All authors contributed to the interpretation of data. The corresponding authors attest that all listed authors meet authorship criteria and that no others meeting the criteria have been omitted. All authors read and approved the final manuscript.

\section{Funding}

This work was supported by the National Natural Science Foundation of China (project no. 81974490) and 2019 Irma and Paul Milstein Program for Senior Health Research Project Award. The funders had no role in study design, data collection and analysis, decision to publish, or reparation of the manuscript.

\section{Availability of data and materials}

Original survey datasets from the HRS, the ELSA, and the CHARLS are freely available to all bonafide researchers. Access to data can be obtained via visiting their websites (https://hrs.isr.umich.edu/data-products, https://beta. ukdataservice.ac.uk/datacatalogue/series/series?id = 200011, and http://charls. pku.edu.cn/pages/data/111/zh-cn.html). The data can also be obtained on request (xiewuxiang@hsc.pku.edu.cn).

\section{Declarations}

\section{Ethics approval and consent to participate}

The HRS, the ELSA, and the CHARLS were approved by the Behavioral Sciences Committee institutional review board at the University of Michigan, the London Multicentre Research Ethics Committee, and the Peking University Institutional Review Board, respectively. All participants provided written informed consent.

\section{Consent for publication}

Not applicable.

\section{Competing interests}

The authors declare that they have no competing interests.

\section{Author details}

${ }^{1}$ Peking University Clinical Research Institute, Peking University First Hospital, Beijing, China. ${ }^{2}$ PUCRI Heart and Vascular Health Research Center at Peking University Shougang Hospital, Beijing, China. ${ }^{3}$ Key Laboratory of Molecular Cardiovascular Sciences (Peking University), Ministry of Education, Beijing, China. ${ }^{4}$ Department of Epidemiology and Biostatistics, School of Public Health, Imperial College London, London, UK. ${ }^{5}$ Department of Geriatric Psychiatry, Affiliated Wuhan Mental Health Center, Tongji Medical College of Huazhong University of Science \& Technology, Wuhan, China. ${ }^{6}$ National School of Development, Peking University, Beijing, China.

\section{Received: 3 August 2021 Accepted: 21 October 2021}

Published online: 01 November 2021

\section{References}

1. Whelton PK, Carey RM, Aronow WS, Casey DE, Collins KJ, Himmelfarb CD, et al. 2017 ACC/AHA/AAPA/ABC/ACPM/AGS/APhA/ASH/ASPC/NMA/PCNA Guideline for the Prevention, Detection, Evaluation, and Management of High Blood Pressure in Adults: A Report of the American College of Cardiology/American Heart Association Task Force on Clinical Practice Guidelines. Hypertension. 2018;71(6):e13-e115. https://doi.org/10.1161/HYP. 0000000000000065.

2. Williams B, Mancia G, Spiering W, Rosei EA, Azizi M, Burnier M, et al. 2018 ESC/ESH Guidelines for the management of arterial hypertension: The Task Force for the management of arterial hypertension of the European Society of Cardiology and the European Society of Hypertension: The Task Force for the management of arterial hypertension of the European Society of Cardiology and the European Society of Hypertension. J Hypertens. 2018; 36(10):1953-2041. https://doi.org/10.1097/HJH.0000000000001940.
3. Christina P. World Alzheimer Report 2018: The state of the art of dementia research: New frontiers. 2018. https://www.alzint.org/resource/world-a Izheimer-report-2018/. Accessed 10 Jan 2021.

4. Livingston G, Huntley J, Sommerlad A, Ames D, Balard C, Banerjee S, et al. Dementia prevention, intervention, and care: 2020 report of the Lancet commission. Lancet. 2020;396(10248):413-46. https://doi.org/10.1016/S01406736(20)30367-6.

5. Qiu C, Winblad B, Fratiglioni L. The age-dependent relation of blood pressure to cognitive function and dementia. Lancet Neurol. 2005;4(8):48799. https://doi.org/10.1016/S1474-4422(05)70141-1.

6. Ou YN, Tan CC, Shen XN, Xu W, Hou XH, Dong Q, et al. Blood pressure and risks of cognitive impairment and dementia: a systematic review and metaanalysis of 209 prospective studies. Hypertension. 2020;76(1):217-25. https:// doi.org/10.1161/HYPERTENSIONAHA.120.14993.

7. Kivipelto M, Helkala EL, Hanninen T, Laakso MP, Hallikainen M, Alhainen K, et al. Midlife vascular risk factors and late-life mild cognitive impairment: a population-based study. Neurology. 2001;56(12):1683-9. https://doi.org/1 0.1212/WNL.56.12.1683.

8. Sonnega A, Faul JD, Ofstedal MB, Langa KM, Phillips JW, Weir DR. Cohort Profile: the Health and Retirement Study (HRS). Int J Epidemiol. 2014;43(2): 576-85. https://doi.org/10.1093/ije/dyu067.

9. The Health and Retirement Study. HRS https://hrs.isr.umich.edu/dataproducts. Accessed 21 Sept 2020.

10. Steptoe A, Breeze E, Banks J, Nazroo J. Cohort profile: the English longitudinal study of ageing. Int J Epidemiol. 2013;42(6):1640-8. https://doi. org/10.1093/ije/dys168.

11. Steptoe A, Banks J, Batty D, Coughlin K, Crawford R, Marmot M, et al. The English Longitudinal Study of Ageing: ELSA. https://beta.ukdataservice.ac.uk/ datacatalogue/series/series?id=200011. Accessed 21 Sept 2020

12. Zhao Y, Hu Y, Smith JP, Strauss J, Yang G. Cohort profile: the China Health and Retirement Longitudinal Study (CHARLS). Int J Epidemiol. 2014;43(1):618. https://doi.org/10.1093/ije/dys203.

13. Zhao Y, Strauss J, Yang G, Hu P, Crimmins E, Park A, et al. The China Health and Retirement Longitudinal Study: CHARLS. http://charls.pku.edu.cn/pages/ data/111/zh-cn.html. Accessed 21 Sept 2020

14. Mindell J, Biddulph JP, Hirani V, Stamatakis E, Craig R, Nunn S, et al. Cohort profile: the health survey for England. Int J Epidemiol. 2012;41(6):1585-93. https://doi.org/10.1093/ije/dyr199.

15. Dregan A, Stewart R, Gulliford MC. Cardiovascular risk factors and cognitive decline in adults aged 50 and over: a population-based cohort study. Age Ageing. 2013;42(3):338-45. https://doi.org/10.1093/ageing/afs166.

16. Levine DA, Galecki AT, Langa KM, Unverzagt FW, Kabeto MU, Giordani B, et al. Trajectory of cognitive decline after incident stroke. JAMA. 2015;314(1): 41-51. https://doi.org/10.1001/jama.2015.6968.

17. Xu H, Zhang Z, Li L, Liu J. Early life exposure to China's 1959-61 famine and midlife cognition. Int J Epidemiol. 2018:47(1):109-20. https://doi.org/10.1 093/ije/dyx222.

18. Zheng F, Yan L, Yang Z, Zhong B, Xie W. HbA1C, diabetes and cognitive decline: the English Longitudinal Study of Ageing. Diabetologia. 2018;61(4): 839-48. https://doi.org/10.1007/s00125-017-4541-7

19. Xie W, Zheng F, Yan L, Zhong B. Cognitive decline before and after incident coronary events. J Am Coll Cardiol. 2019;73(24):3041-50. https://doi.org/10.1 016/j.jacc.2019.04.019.

20. Hua R, Ma Y, Li C, Zhong B, Xie W. Low levels of low-density lipoprotein cholesterol and cognitive decline: Science Bulletin; 2020.

21. Zheng F, Zhong B, Song X, Xie W. Persistent depressive symptoms and cognitive decline in older adults. Br J Psychiatry. 2018;213(5):638-44. https:// doi.org/10.1192/bjp.2018.155

22. Li C, Miles T, Shen L, Shen Y, Liu T, Zhang M, et al. Early-life exposure to severe famine and subsequent risk of depressive symptoms in late adulthood: the China Health and Retirement Longitudinal Study. Br J Psychiatry. 2018;213(4):579-86. https://doi.org/10.1192/bjp.2018.116.

23. Carroll MD, Fryar CD, Nguyen DT. Total and high-density lipoprotein cholesterol in adults: United States, 2015-2016. NCHS Data Brief. 2017;290:1-8.

24. Ma Y, Liang L, Zheng F, Shi L, Zhong B, Xie W. Association between sleep duration and cognitive decline. JAMA Netw Open. 2020;3(9).

25. Yu ZB, Zhu Y, Li D, Wu MY, Tang ML, Wang JB, et al. Association between visit-to-visit variability of $\mathrm{HbA}(1 \mathrm{c})$ and cognitive decline: a pooled analysis of two prospective population-based cohorts. Diabetologia. 2020;63(1):85-94. https://doi.org/10.1007/s00125-019-04986-8. 
26. Navarese EP, Kolodziejczak M, Schulze V, Gurbel PA, Tantry U, Lin Y, et al. Effects of proprotein convertase Subtilisin/Kexin Type 9 antibodies in adults with hypercholesterolemia: a systematic review and meta-analysis. Ann Intern Med. 2015;163(1):40-51. https://doi.org/10.7326/M14-2957.

27. Higgins J, Thomas J, Chandler J, Cumpston M, Li T, Page M, et al. Cochrane Handbook for Systematic Reviews of Interventions (Version 6.2). 2021. https://training.cochrane.org/handbook/current. Accessed 10 Sept 2021.

28. Hughes D, Judge C, Murphy R, Loughlin E, Costello M, Whiteley W, et al. Association of blood pressure lowering with incident dementia or cognitive impairment: a systematic review and meta-analysis. JAMA. 2020;323(19): 1934-44. https://doi.org/10.1001/jama.2020.4249.

29. Gottesman RF, Schneider AL, Albert M, Alonso A, Bandeen-Roche K, Coker L, et al. Midlife hypertension and 20-year cognitive change: the atherosclerosis risk in communities neurocognitive study. JAMA Neurol. 2014;71(10):121827. https://doi.org/10.1001/jamaneurol.2014.1646.

30. Goldstein FC, Levey Al, Steenland NK. High blood pressure and cognitive decline in mild cognitive impairment. J Am Geriatr Soc. 2013;61(1):67-73. https://doi.org/10.1111/jgs.12067.

31. Norman GR, Sloan JA, Wyrwich KW. Interpretation of changes in healthrelated quality of life: the remarkable universality of half a standard deviation. Med Care. 2003;41(5):582-92. https://doi.org/10.1097/01.MLR. $0000062554.74615 .4 \mathrm{C}$.

32. Holden G. Statistical Power Analysis for the Behavioral-Sciences, 2nd Edition - Cohen. J Soc Work Health Care. 1993;18(2):131-2.

33. Mossello E, Pieraccioli M, Nesti N, Bulgaresi M, Lorenzi C, Caleri V, et al. Effects of low blood pressure in cognitively impaired elderly patients treated with antihypertensive drugs. JAMA Intern Med. 2015;175(4):578-85. https://doi.org/10.1001/jamainternmed.2014.8164.

34. Liao D, Cooper L, Cai J, Toole JF, Bryan NR, Hutchinson RG, et al. Presence and severity of cerebral white matter lesions and hypertension, its treatment, and its control. The ARIC Study. Atherosclerosis Risk in Communities Study. Stroke. 1996;27(12):2262-70. https://doi.org/10.1161/01. STR.27.12.2262.

35. O'Rourke MF, Safar ME. Relationship between aortic stiffening and microvascular disease in brain and kidney: cause and logic of therapy. Hypertension. 2005;46(1):200-4. https://doi.org/10.1161/01.HYP.0000168052. 00426.65 .

36. Beauchet O, Celle S, Roche F, Bartha R, Montero-Odasso M, Allali G, et al. Blood pressure levels and brain volume reduction: a systematic review and meta-analysis. J Hypertens. 2013;31(8):1502-16. https://doi.org/10.1097/HJH. Ob013e32836184b5.

37. Maule S, Caserta M, Bertello C, Verhovez A, Naso D, Bisbocci D, et al. Cognitive decline and low blood pressure: the other side of the coin. Clin Exp Hypertens. 2008;30(8):711-9. https://doi.org/10.1080/10641960802 573344

38. Elias PK, Elias MF, Robbins MA, Budge MM. Blood pressure-related cognitive decline: does age make a difference? Hypertension. 2004;44(5):631-6. https://doi.org/10.1161/01.HYP.0000145858.07252.99.

39. Streit S, Poortvliet RKE, Elzen W, Blom JW, Gussekloo J. Systolic blood pressure and cognitive decline in older adults with hypertension. Ann Fam Med. 2019;17(2):100-7. https://doi.org/10.1370/afm.2367.

40. Li G, Rhew IC, Shofer JB, Kukull WA, Breitner JC, Peskind E, et al. Age-varying association between blood pressure and risk of dementia in those aged 65 and older: a community-based prospective cohort study. J Am Geriatr Soc. 2007;55(8):1161-7. https://doi.org/10.1111/j.1532-5415.2007.01233.x.

41. Kuller LH, Lopez OL, Jagust WJ, Becker JT, DeKosky ST, Lyketsos C, et al. Determinants of vascular dementia in the Cardiovascular Health Cognition Study. Neurology. 2005;64(9):1548-52. https://doi.org/10.1212/01.WNL.00001 60115.55756.DE.

42. Taylor C, Tillin T, Chaturvedi N, Dewey M, Ferri CP, Hughes A, et al. Midlife hypertensive status and cognitive function 20 years later: the Southall and Brent revisited study. J Am Geriatr Soc. 2013;61(9):1489-98. https://doi.org/1 $0.1111 /$ jgs. 12416

43. Emdin CA, Rothwell PM, Salimi-Khorshidi G, Kiran A, Conrad N, Callender T, et al. Blood pressure and risk of vascular dementia: evidence from a primary care registry and a cohort study of transient ischemic attack and stroke. Stroke. 2016;47(6):1429-35. https://doi.org/10.1161/STROKEAHA.116.012658.

44. Launer LJ, Masaki K, Petrovitch H, Foley D, Havlik RJ. The association between midlife blood pressure levels and late-life cognitive function. The Honolulu-Asia Aging Study. JAMA. 1995;274(23):1846-51. https://doi.org/10.1 001/jama.1995.03530230032026.
45. Lattanzi S, Brigo F, Vernieri F, Silvestrini M. Visit-to-visit variability in blood pressure and Alzheimer's disease. J Clin Hypertens. 2018;20(5):918-24. https://doi.org/10.1111/jch.13290.

46. Qin B, Viera AJ, Muntner P, Plassman BL, Edwards LJ, Adair LS, et al. Visit-tovisit variability in blood pressure is related to late-life cognitive decline. Hypertension. 2016;68(1):106-13. https://doi.org/10.1161/HYPERTENSIONA HA.116.07494.

\section{Publisher's Note}

Springer Nature remains neutral with regard to jurisdictional claims in published maps and institutional affiliations.
Ready to submit your research? Choose BMC and benefit from:

- fast, convenient online submission

- thorough peer review by experienced researchers in your field

- rapid publication on acceptance

- support for research data, including large and complex data types

- gold Open Access which fosters wider collaboration and increased citations

- maximum visibility for your research: over $100 \mathrm{M}$ website views per year

At BMC, research is always in progress.

Learn more biomedcentral.com/submissions 